\title{
The Future of the Portuguese Health System
}

\author{
O Futuro do Sistema de Saúde Português
}

Nigel CRISP $\square^{1,2}$
Acta Med Port 2015 May-Jun;28(3):277-280

Keywords: Forecasting; Health Policy; National Health Programs; Portugal.

Palavras-chave: Política de Saúde; Portugal; Previsões; Serviço Nacional de Saúde.

The Portuguese health system has considerable strengths and an impressive track record of success, but is facing severe challenges due to increasing demand and restricted funding. Its continuing success will depend on how citizens and clinicians respond to these challenges as well as on a clear vision for the future and good collective leadership from health professionals, politicians and others in wider society.

This paper briefly sets out the background by describing the health of the population and the performance of the health system before going on to outline a vision and a strategy for the future. First, however, I would note that the health system has been under enormous strain in recent years with some cutbacks in services, and that health workers have had both their pay and their pension entitlements reduced. It is to the great credit of all concerned that the service has survived so well and that patients have for the most part continued to be able to get the treatments they need.

My perspective in this article has been formed by the time I have spent in Portugal over the last two years during which I have been privileged to get to know Portugal and the Portuguese health system as the chair of the Gulbenkian Foundation's Commission on the Future of Health in Portugal. Our task as a Commission was to "look forward 25 years to create a new vision for health and health care to describe what this would mean in practice and set out how it might be achieved and sustained". ${ }^{1}$ I came to this role having run the NHS in England for 6 years and subsequently worked mainly in Africa for the last few years.

\section{The health of the population}

The future of the health system will depend of course on the nature of the health problems which the country has to deal with. The health of the population has improved enormously since the country became a democracy. Life expectancy is approaching the European average and there have been particular improvements in child health, where Portugal now has one of the best perinatal mortality rates in Europe. These improvements are attributed by the European Observatory to a combination of factors: "improved access to an expanding health network, continued political commitment, and economic growth, which led to improved living standards and increasing investment in healthcare". ${ }^{2}$

Forty years on, Portugal today is experiencing many of the same health risks and problems as other western countries. It has an ageing population, increasing levels of long term chronic conditions or non-communicable diseases and high levels of obesity. The best estimate is that about $54 \%$ of the population or 5.4 million Portuguese people suffer from at least one chronic disease in Portugal (Campos L. Unpublished calculations from Portuguese Ministry of Health database 2012 covering 693993 patients). An estimate of the proportion of the population suffering from respectively $1-2,3-4$ and 5 chronic diseases is shown on Fig. 1.

These proportions are broadly comparable to those in other western European countries. However, there are some distinctive features about health in Portugal. There are high levels of diabetes, stroke and HIVIAIDS compared to other Western European countries. Portugal has the highest prevalence of diabetes in Europe and it is continuing to grow rapidly with about 70000 new diagnoses a year. Diabetes and the complications of diabetes are costing the

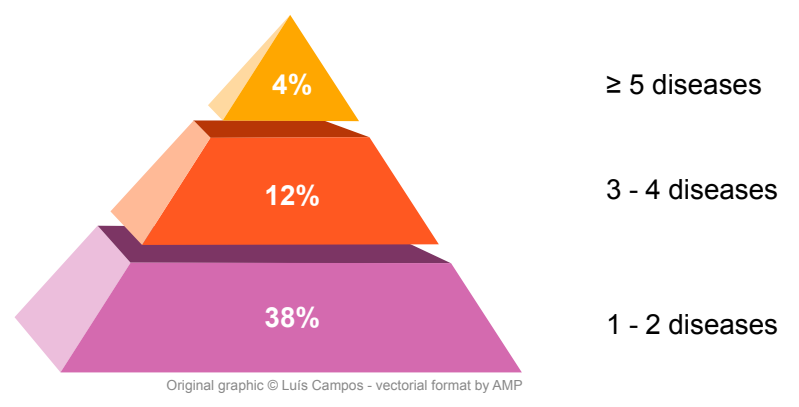

Figure 1 - The proportion of the Portuguese population suffering from chronic diseases

\footnotetext{
1. Independent Member. United Kingdom House of Lords. London. United Kingdom.

2. Honorary Professor. London School of Hygiene and Tropical Medicine. London. United Kingdom.

$\bowtie$ Autor correspondente: Nigel Crisp. crisp@parliament.uk

Recebido: 17 de Maio 2015 - Aceite: 18 de Junho 2015| Copyright @ Ordem dos Médicos 2015
} 
country about $10 \%$ of its health budget or around $1 \%$ of GDP. ${ }^{3}$ There is also evidence of high levels of obesity in all age groups, lower levels of mental well-being than in other OECD countries and very high use of anti-depressants. ${ }^{4,5}$

One of the most telling comparisons with other countries is that Portuguese men and women can only expect on average 6.6 and 6 years of healthy life respectively after the age of 65 whilst Norwegian men and women can look forward to 15.4 and 15.9. Life expectancy is similar between the countries but the Norwegians will be healthier for longer. These comparisons are shown in Fig. 2.

The health system has to deal with an ageing population.

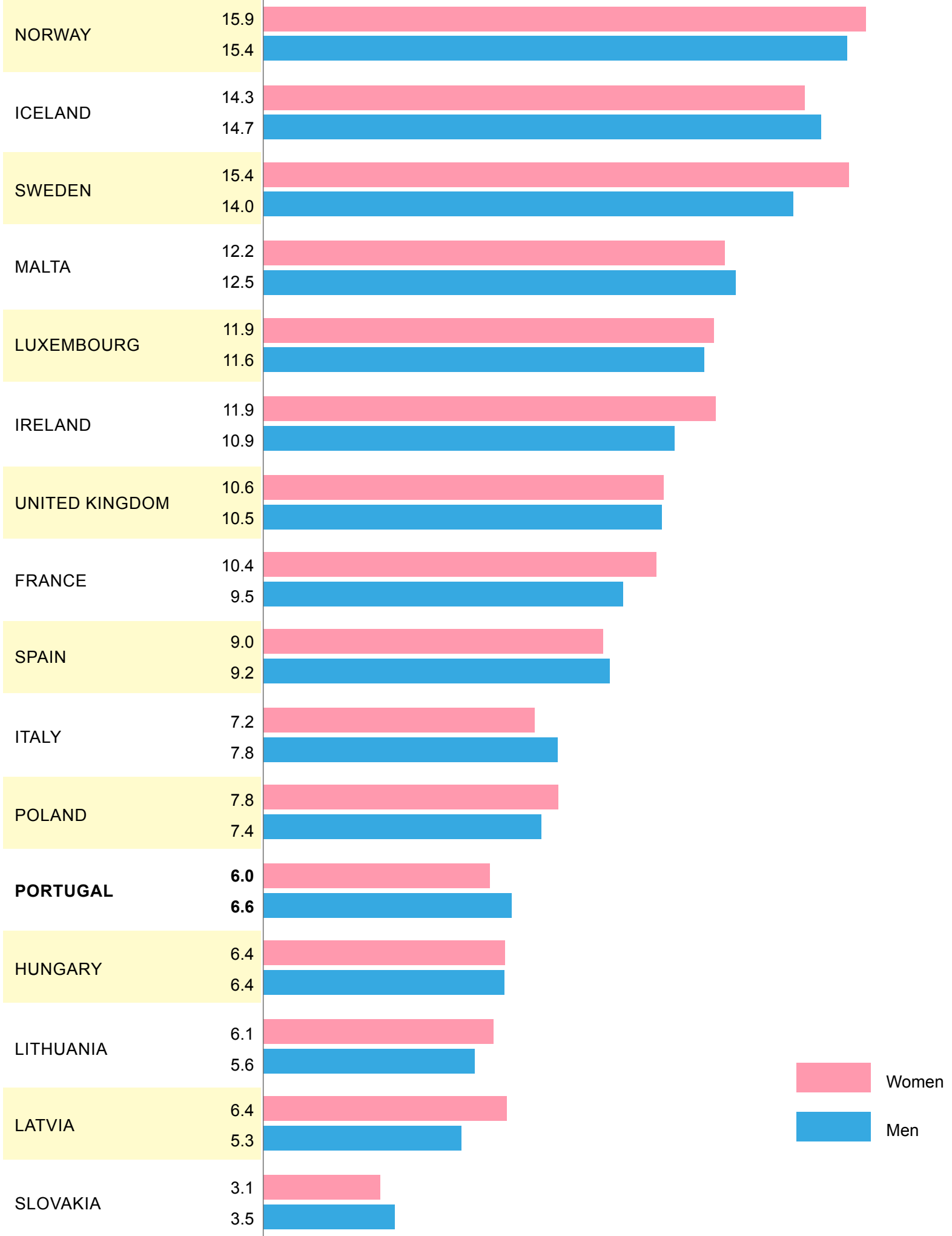

Figure 2 - Healthy years of life after age 65 
Many of its young people, particularly graduates, are emigrating permanently or temporarily in search of employment. This has long been a trend in Portugal but the trend is accelerating due to the recent economic pressures and the population has begun to fall. Emigration is thus aggravating a situation where the Portuguese fertility rate currently stands at 1.32 - amongst the lowest in the world - and the proportion of people of working age in the population is falling.

\section{The Portuguese health system}

Portugal is fortunate in having high levels of clinical skills amongst its professionals and a Serviço Nacional de Saúde (SNS) that is very well supported by the public. It is particularly strong in hospital services but less strong in primary and continuing care - with many patients using hospital services, such as the emergency room, because they cannot access primary care or have little faith in its quality. Whilst there are many very good services around the country, such data as is available suggests there is wide variation in clinical practice and outcomes.

This variation is reflected in policies - there are 3 competing systems of accreditation, for example - and has been complicated by the many reforms there have been over the years. Some were only partially implemented and new reforms were later introduced on top of them leading to considerable differences in provision around the country. Thus, for example, the primary health care reforms of the last few years only cover part of the country even though there appears to be considerable support for them and some evidence of their success.

It is only recently that clinical guidelines and protocols are being introduced in an effort to improve the consistency and quality of care. This is part of a broader picture in which there is a lack of data compared to other Western European countries, poor quality in what is available and a lack of transparency. As a result, the Commission decided to emphasise in its recommendations the importance of evidence, systematic quality improvement and good data openly available.

Turning to finance, there is little scope to raise taxes except perhaps 'sin taxes' on alcohol, tobacco and other unhealthy products. Equally, there is no scope to increase co-payments because, as Fig. 3 shows, 'out of pocket payments' - those not covered by insurance or the SNS are very high in Portugal amounting to $27 \%$ of total health expenditure. This means that the emphasis needs to be firmly on managing costs by reducing waste and duplication, re-designing services and improving value for money.

\section{A vision and strategy for the future}

This very brief summary allows one to draw out some key points:

- The biggest health issues facing Portugal come from an aging population with multiple chronic diseases - and a primary goal of the health system must be to reduce the years of ill health experienced by so many older people.

- Better and more community based models of care need to be introduced for managing people with

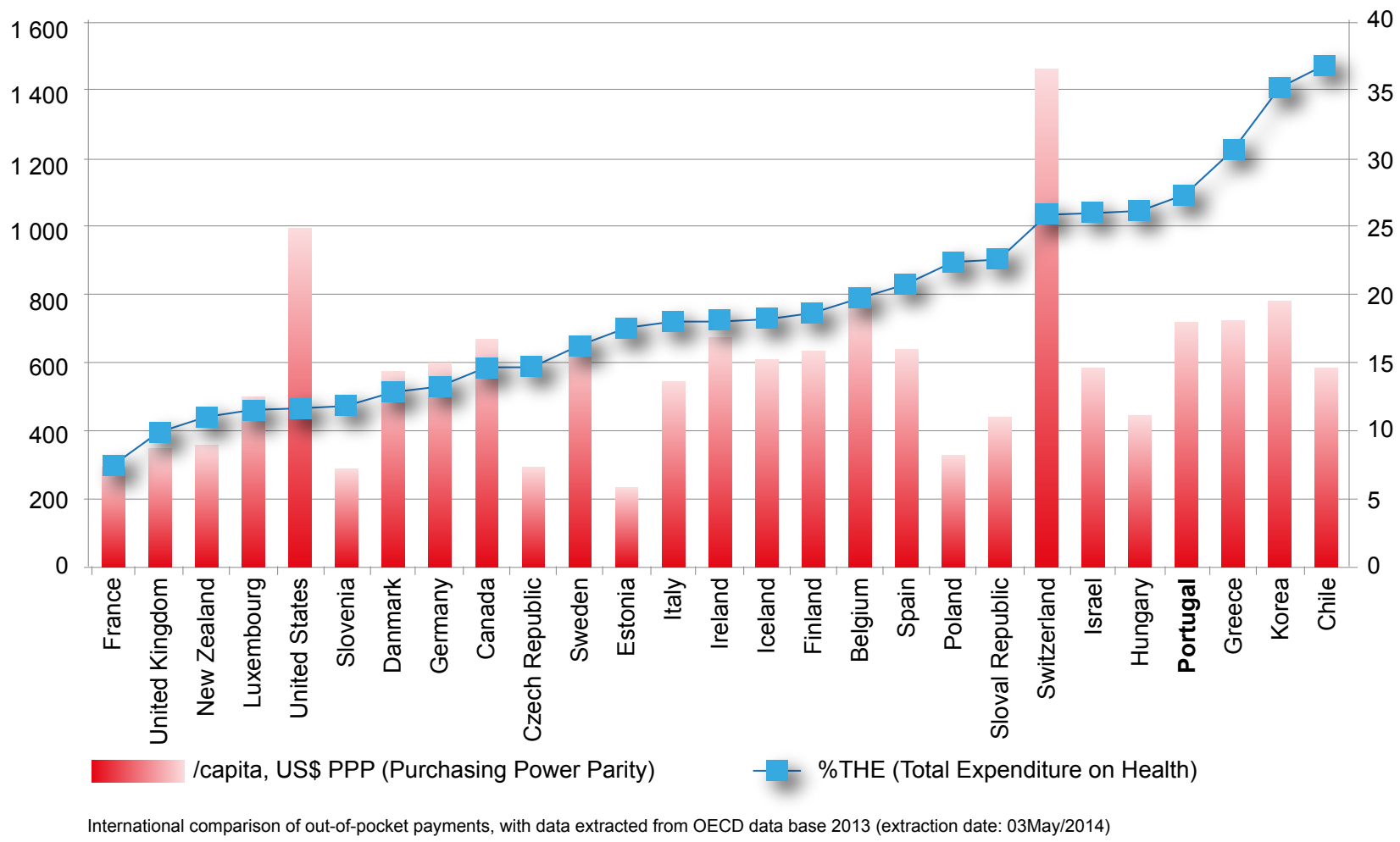

Figure 3 - Out of pocket payments for selected OECD countries 2013 
chronic diseases - as part of an expansion of primary, community and home based services.

- There needs to be a much greater emphasis on quality improvement as a means of reducing inappropriate clinical variation and reducing the waste caused by inappropriate treatment, duplication of services and poor quality care - hospital acquired infections alone are costing the nation an estimated Euro 280 million a year and causing a great deal of suffering.

These conclusions suggest the need for a two part approach to health in Portugal - promoting health and preventing diseases on the one hand and reforming the SNS on the other:

\section{Promoting health and preventing disease.}

The SNS will not be sustainable unless we take some of the strain off it with a sustained and systematic approach to preventing ill health and promoting physical and mental health and well-being. The SNS cannot do this by itself.

The World Health Organisation says "modern societies actively market unhealthy lifestyles". This needs to be turned on its head so that Portugal develops a 'health creating society'. There is an opportunity to bring together everyone who affects health - employers, educators, designers, local authorities and citizens themselves - to improve the health of the whole country. Everyone has a role to play.

\section{Reforming the SNS}

At the same time, in the words of the Commission, the
SNS has to "transition from today's hospital-centred and illness based system where things are done to or for a patient to a person-centred and health based one where citizens are partners in health promotion and health care. It will use the latest knowledge and technology and offer access to advice and high quality services in homes and communities as well as in clinics and specialist centres. "This vision maintains the founding values of the SNS and builds on the strengths of the current system, the skills of health professionals and the achievements of the past - but it demands new approaches, different infrastructure and a lower and more sustainable cost base."1

Change on this enormous scale requires a clear long term vision and leadership from across society. The SNS cannot do it by itself. Above all I believe this needs bold and visionary political leadership which is ready to set differences aside, able to articulate and debate this vision in public and bring people together to build a 'health creating society'.

All Western countries face these same sorts of issues. Portugal can lead the way by showing how they can be tackled.

\section{CONFLICTS OF INTEREST}

None stated.

\section{FUNDING SOURCES}

The Gulbenkian Foundation supported the work on which this article is based.

Observatory of Portugal. Lisbon: National Diabetes Observatory of Portugal; 2012.

4. OECD Better Life Index. [consulted 2015 Jun 16]. Available at: http:// www.oecdbetterlifeindex.org/countries/portugal/.

5. Eurobarometer. Special Report on Mental Health. Brussels: TNS Opinion and Social; 2010. 


\section{Nigel CRISP \\ The Future of the Portuguese Health System}

Acta Med Port 2015:28:277-280

Publicado pela Acta Médica Portuguesa, a Revista Científica da Ordem dos Médicos

Av. Almirante Gago Coutinho, 151

1749-084 Lisboa, Portugal.

Tel: +351218428 215

E-mail: submissao@actamedicaportuguesa.com

www.actamedicaportuguesa.com

ISSN:0870-399X | e-ISSN: 1646-0758

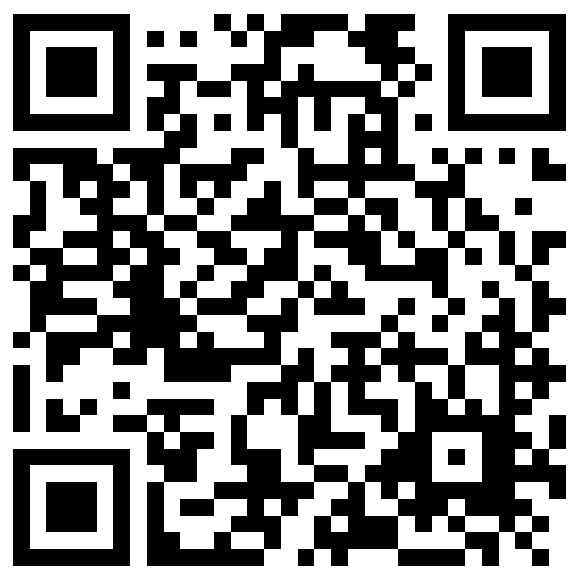

